\title{
The Impact of Resilience on the Psychological Health of Disadvantaged Children: The Mediating Role of Coping Styles and Core Self-Evaluation
}

\author{
Chenxi $\mathrm{Li}^{1, *}$ Chao $\mathrm{Ma}^{1,2}$ Haidong Zhu ${ }^{1}$ Chao Song ${ }^{3}$ Zhijiang Liang ${ }^{1}$ Jinli Wei ${ }^{4}$
}

\author{
${ }^{1}$ Normal College, Shihezi University, Shihezi, Xinjiang 832003, China \\ ${ }^{2}$ Centre for Applied Psychological Research, Shihezi University, Shihezi, Xinjiang, China \\ ${ }^{3}$ Ghent University, Ghent, Belgium \\ ${ }^{4}$ Third Division 44 Regiment Middle School, Tumxuk, Xinjiang, China \\ *Corresponding author. Email: 2943418965@qq.com
}

\begin{abstract}
Objective: Based on the environment-individual interaction model and the "evaluation-coping" theory, the relationship between Resilience, Coping Styles, Core Self-evaluation and psychological health of disadvantaged children was explored to provide some theoretical support for psychological health intervention research. Methods: Resilience Scale for Chinese Adolescent (RSCA), core self-evaluation Scale (CSES), Simplified Coping Style Questionnaire (SCSQ), General Health Questionnaire (GHQ-12) were used to conduct a questionnaire survey among 618 middle school students in South Xinjiang. Results: First, GHQ-12 scores were negatively correlated with RSCA, CSES, and SCSQ scores ( $r=-$ $0.57 / r=-0.56 / r=-0.49, P<0.001)$, and positively correlated with the level of psychological health; second, coping styles is a mediator between resilience and psychological health (mediator effect value is -0.04); third, core self-evaluation is a mediator between coping styles and psychological health, there is "resilience - coping styles - core self-evaluation - psychological health" path. Conclusion: Resilience can directly predict the psychological health of disadvantaged children, and indirectly predict psychological health level through chain mediation of coping styles - core self-evaluation.
\end{abstract}

Keywords: resilience, core self-evaluation, coping styles, psychological health, mediator

\section{INTRODUCTION}

Adversity of different risk indexes will inevitably occur during the growth of adolescents, and risk gradient effects have been shown in studies of poverty, abuse, war, natural disasters, and other risk indexes. However, the adaptive results of adolescents are heterogeneous [1-8]. According to statistics, $80 \%$ of individuals in developing countries who need psychological health care have not received relevant interventions [9], [10]. With the advancement of poverty alleviation work in China, in order to prevent the phenomenon of returning to poverty, the four prefectures in southern Xinjiang, are the key areas of concern. While improving the material conditions, timely intervention measures should be taken to avoid the "scar" effect of poverty disadvantages brought about by physical and psychological health for young people[11-17]. Studies in China and foreign countries have shown that personal changes experienced by adolescents aged 10-15 are more profound than at other stages of life [18]. Adversity in the early period may have programming effects that affect their lifetime development [3], [19], [20], and long-term poverty will decrease children's brain capacity and affects mentality and cognitive development [21], [22]. But why are some children still advancing in the face of adversity? The "challenging" model and the "steel effect" of psychological toughness and related research show that through psychological toughness training, individuals perceive less psychological pain or stress confusion, which can buffer or eliminate the effects of negative events, thereby improving their psychological health level [23-28]. Therefore, exploring the impact mechanism of resilience on the psychological health of disadvantaged children can provide some practical guidance and theoretical basis for the psychological health education and intervention research of vulnerable children.

The environment-individual interaction model in resilience regards the environment as an individual's ecological circle from an ecological perspective, emphasizing the process in which individuals adopt a positive coping style in the face of adversity will form a positive result [29]. Empirical research also shows that 
the less resources available to cope with adversity, the fewer positive coping styles, and the increase in negative coping styles is negatively related to psychological health [30], [31]. Resilience is an important ability to adapt to adversity, and the coping style is the behavior adopted by individuals when facing adversity [27]. Therefore, this study proposes hypothesis $\mathrm{H} 1$ : coping style is an intermediary variable between resilience and psychological health of disadvantaged children.

So how does coping style affect psychological health? Lazarus' "evaluation-coping" theory and empirical research show that individuals with high core self-evaluation rarely adopt avoidant coping styles and believe that they have the ability to solve the problems they face [32], which can reduce their anxiety and depression, reduce the occurrence of negative behaviors, and help maintain the psychological health of adolescents [33]. Core self-evaluation refers to the basic cognition and evaluation of the self that gradually develops as the individual continuously solves problems during the growth process [34], which indicates that the core self-evaluation level is unstable due to the interaction between the individual and the environment [35], especially for teenagers aged 0-15. So how to choose the order of intervention according to the characteristics of adolescents' physical and mental development in actual teaching? Is the intervention that first focuses on coping with tendencies a more effective measure to steadily improve core self-evaluation and thereby improve psychological health? Combining previous studies, this study proposes hypothesis $\mathrm{H} 2$ : core self-evaluation is an intermediary variable between coping style and psychological health of junior high school students.

In summary, in order to stimulate the potential of disadvantaged children and enhance their psychological health, and to explore more effective interventions, this study integrates the "evaluation-response" theory and empirical research based on the environment-individual interaction model, mainly explores how "resilience" affects psychological health, and examines the mediating role of coping style and the chained mediating role of coping style and core self-evaluation. This not only helps to understand the mechanism between resilience and psychological health from the perspective of coping style and self-evaluation, but also provides empirical evidence and theoretical support for intervention research to improve adolescents' resilience and further improve their psychological health, and then promote national unity and strengthening national exchanges and provide guidance with important scientific and practical value.

\section{OBJECTS AND METHODS}

\section{A. Objects}

The cluster sampling method was adopted to select students from six classes in the seventh and eighth grades of a middle school in southern Xinjiang as the test subjects. On-site testing and recovery questionnaires were issued, and 650 questionnaires were distributed. The effective rate is $95.08 \%$. Among them, 302 were male students, accounting for $48.87 \%$; 316 were female students, accounting for $51.13 \%$; and the average age was $(14.1 \pm 1.437)$.

\section{B. Tools}

1) Resilience Scale for Chinese Adolescent (RSCA): Resilience Scale for Chinese Adolescent (RSCA) compiled by $\mathrm{Hu}$ Yueqin and Gan Yiqun was used. A total of 27 items including 5 dimensions (family support, interpersonal assistance, goal focus, emotional control, positive cognition), 1-5 grades, 1 (completely inconsistent) $\sim 5$ (completely consistent), a total of 135 The higher the total score, the higher the level of resilience [36]. The internal consistency reliability of the scale was 0.77 , and the retest reliability was 0.86 .

2) Core Self-evaluation Scale (CSES): The Core Self-evaluation Scale (CSES) revised by Judge etc., and Du Jianzheng etc., was used It contains 10 questions, grades 1-5, 1 (completely disagree) $\sim 5$ (completely agree), and the total score is 50 points. The higher the total score, the higher the core self-evaluation level [37]. The internal consistency reliability of the scale was 0.79 , and the retest reliability was 0.83 .

3) Simplified Coping Style Questionnaire (SCSQ): Simplified Coping Style Questionnaire (SCSQ) compiled by Xie Yaning was used, with a total of 20 questions, which was divided into two dimensions of positive response and negative response. The score ranges from 0 to 3,0 (not taken) to 3 (usually taken), and the difference between the score of the positive coping style and the score of the negative coping style is used as the coping style score. A higher coping propensity score indicates a more proactive coping style [38]. The internal consistency reliability of the scale was 0.61 , and the retest reliability was 0.68 .

4) General health Questionnaire (GHQ-12): This used the General health Questionnaire (GHQ-12) compiled by Goldberg, with a total of 12 items, a score of $0-3,0$ (never) to 3 (often), with a total score of 36 points. The higher the total score, the lower the level of psychological health. A total score $\geq 15$ indicates a tendency to have mental problems [39]. The internal consistency reliability of the scale was 0.76 , and the retest reliability was 0.78 . 


\section{Quality control}

There may be common method deviation in this study, so Harman's single factor method test was used to (unrotated principal component factor analysis of all items in the scale) show that there are a total of 23 factors with a characteristic root greater than 1 , and the first factor's explanatory variation is $11.06 \%$, which is $40 \%$ below the critical value. From this, it was determined that the common method deviation did not cause serious errors in this study. In order to ensure the reliability of this study, the following measures were taken during the research: (1) Classes are uniformly tested, and in order to grasp the content and time of the scale, a pre-investigation is first performed on a class; (2) The tester is a major in psychology or pedagogy with unified training, using the same standardized guideline; (3) Anonymous investigation, the respondents are informed of the content, and according to the principle of voluntarism, the confidentiality of the research is emphasized in the guidance section; (4) During the test, if there is any unclear content, the test staff will explain it in time, and the time for filling in the questionnaire is controlled within 30 minutes; (5) In the process of sorting and entering data, the questionnaire contents were checked one by one in a timely manner and uniformly numbered and rechecked. It was found that those with missing items above $20 \%$ did not enter the data entry stage. And it randomly selected $5 \%$ of the input data to check whether it is consistent with the original data and ensured that the consistency is above $95 \%$.

\section{Data processing and analysis}

According to the type of data, the researchers used spss17.0. After controlling demographic factors, Pearson correlation analysis and hierarchical regression were performed on resilience, coping style, core selfevaluation and psychological health factors. Amos 23.0 was used to construct the structural equation model, and the non-parametric percentile Bootstrap method was used to test the significance of the mediating effect by bias correction. The difference was statistically significant at $\mathrm{P}<0.05$ or 0.001 .

\section{RESULTS}

A. Correlation analysis of resilience, coping style, core self-evaluation and psychological health

After conducting the Pearson correlation analysis of resilience, coping style, core self-evaluation and psychological health, the results show that resilience was positively correlated with its sub-dimensional target concentration, emotional control, positive cognition, family support, interpersonal assistance and core self-evaluation, coping style and its subdimensional positive coping, $(\mathrm{P}<0.001)$ and was negatively correlated with coping style sub-dimension ( $\mathrm{P}<0.001) ;$ it is negatively correlated with psychological health $(\mathrm{P}<0.001)$, that is, positively correlated with psychological health level. Psychological health was negatively correlated with coping style and positive coping $(\mathrm{P}<0.001)$, which was positively correlated with psychological health; positively correlated with negative coping $(\mathrm{P}<0.001)$, which was negatively correlated with psychological health. (See "Table I")

TABLE I. CORRELATION MATRIX OF RESILIENCE, CORE SELF-EVALUATION, COPING STYLE, AND PSYCHOLOGICAL HEALTH

\begin{tabular}{|c|c|c|c|c|c|c|c|c|c|c|c|c|c|c|}
\hline & $M$ & $S D$ & 1 & 2 & 3 & 3.1 & 3.2 & 3.3 & 3.4 & 3.5 & 4 & 5 & 6 & 6.1 \\
\hline 1 Gender & - & - & 1 & & & & & & & & & & & \\
\hline 2 Age & 14.1 & 1.437 & -0.15 & 1 & & & & & & & & & & \\
\hline 3.RSCA & 90.8 & 12.76 & $0.01 * *$ & $-0.13 * *$ & 1 & & & & & & & & & \\
\hline $\begin{array}{l}\text { 3.1Target } \\
\text { focusing }\end{array}$ & 17.59 & 3.8 & -0.02 & -0.04 & $0.62 * * *$ & 1 & & & & & & & & \\
\hline $\begin{array}{l}3.2 \text { Emotional } \\
\text { control }\end{array}$ & 18.47 & 4.61 & -0.06 & -0.07 & $0.64 * * *$ & $0.19 * * *$ & 1 & & & & & & & \\
\hline $\begin{array}{c}3.3 \text { Positive } \\
\text { cognition } \\
\end{array}$ & 14.4 & 3.0 & 0.08 & -0.05 & $0.38^{* * *}$ & $0.31 * * *$ & 0.03 & 1 & & & & & & \\
\hline $\begin{array}{c}\text { 3.4 Family } \\
\text { support }\end{array}$ & 18.97 & 4.4 & 0.03 & $-0.08 *$ & $0.66^{* * *}$ & $0.27 * * *$ & $0.24 * * *$ & $0.13 * * *$ & 1 & & & & & \\
\hline $\begin{array}{l}\text { 3.5Interperso } \\
\text { nal assistance }\end{array}$ & 18.76 & 5.0 & 0.03 & $-0.13 * *$ & $0.68^{* * *}$ & $0.23 * * *$ & $0.34 * * *$ & $-0.03 * * *$ & $0.3 * * *$ & 1 & & & & \\
\hline 4 CSES & 32.93 & 6.24 & $-0.08 *$ & $-0.13^{* *}$ & $0.62 * * *$ & $0.41 * * *$ & $0.48 * * *$ & $0.25 * * *$ & $0.34 * * *$ & $0.4 * * *$ & 1 & & & \\
\hline $5 \mathrm{GHQ}-12$ & 15.17 & 5.06 & 0.06 & $0.13 * *$ & $-0.59 * * *$ & $-0.35 * * *$ & $-0.41 * * *$ & $-0.26^{* * *}$ & $-0.39 * * *$ & $-0.35 * * *$ & $-0.56 * * *$ & 1 & & \\
\hline $6 S C S Q$ & -0.27 & 1.28 & 0.04 & $-0.09 *$ & $0.53^{* * *}$ & $0.41 * * *$ & $0.28 * * *$ & $0.33 * * *$ & $0.3 * * *$ & $0.32 * * *$ & $0.45 * * *$ & $-0.49 * * *$ & 1 & \\
\hline $\begin{array}{l}\text { 6.1 Positive } \\
\text { coping }\end{array}$ & 2.27 & 1.0 & -0.03 & -0.07 & $0.29 * * *$ & $0.29 * * *$ & 0.07 & $0.28 * * *$ & $0.17 * * *$ & $0.19 * * *$ & $0.25 * * *$ & $-0.26 * * *$ & $0.64 * * *$ & 1 \\
\hline $\begin{array}{l}6.2 \text { Negative } \\
\text { coping }\end{array}$ & -2.86 & 1.0 & $-0.08 *$ & 0.04 & $-0.23^{* * *}$ & $-0.23 * * *$ & $-028 * * *$ & $-0.15 * * *$ & $-0.2 * * *$ & $-0.2 * * *$ & $-0.32 * * *$ & $0.36^{* * *}$ & $-0.64 * * *$ & $0.18 * * *$ \\
\hline
\end{tabular}


B. Regression analysis of resilience, coping style, core self-evaluation and psychological health

Transform each predictor into a Z-score to control the effects of gender and age. According to the mediation effect test process proposed by Wen Zhonglin et al. [40], the researchers studied the method of stratified regression to test whether there is a mediating role between coping style and core selfevaluation and resilience and psychological health.

Regression analysis shows that when resilience and coping style and core self-evaluation enter the equation, coping style and core self-evaluation play the part of the mediating effect respectively. Hypothesis 1 is supported that coping style mediate between resilience and psychological health. It also shows that core selfevaluation plays a mediating role between resilience and psychological health. When the three enter the regression equation at the same time, the absolute value of the resilience regression coefficient decreases, indicating that coping style and core self-evaluation play a role at the same time. Considering that the direct effects of resilience on psychological health are still significant, it shows that coping style and core selfevaluation are in part of the mediating role between resilience and psychological health. That is, Hypothesis 2 is supported, and core self-evaluation plays a mediating role between coping style and psychological health. (See "Table II")

TABLE II. REGRESSION ANALYSIS OF RESILIENCE, CORE SELF-EVALUATION, COPING STYLE AND PSYCHOLOGICAL HEALTH

\begin{tabular}{|c|c|c|c|c|c|c|c|c|c|c|}
\hline \multirow[t]{2}{*}{ Variable } & \multicolumn{2}{|c|}{$\begin{array}{l}\text { GHQ-12 } \\
\text { (Step 1) }\end{array}$} & \multicolumn{4}{|c|}{$\begin{array}{c}\text { SCSQ, CSES } \\
\quad(\text { Step 2) }\end{array}$} & \multicolumn{2}{|c|}{$\begin{array}{l}\text { GHQ-12 } \\
\text { (Step 3) }\end{array}$} & \multicolumn{2}{|c|}{$\begin{array}{l}\text { GHQ-12 } \\
\text { (Step 4) }\end{array}$} \\
\hline & $\beta$ & $t$ & $\beta$ & $t$ & $\beta$ & $t$ & $\beta$ & $t$ & $\beta$ & $t$ \\
\hline Age & 0.08 & 1.94 & 0.03 & 0.78 & -0.1 & $-2.54 * *$ & 0.04 & 1.41 & 0.64 & $2.06^{*}$ \\
\hline Gender & 0.14 & $3.52 * *$ & -0.08 & $-1.97 *$ & -0.07 & $-3.67 * * *$ & 0.05 & 1.46 & 0.05 & 1.5 \\
\hline$R S C A$ & -0.586 & $-17.67 * * *$ & 0.527 & $15.15^{* * *}$ & 0.622 & $19.48^{* * * *}$ & -0.39 & $-9.75^{* * *}$ & -3.06 & $-7.38 * * *$ \\
\hline$S C S Q$ & & & & & & & -0.25 & $-6.67 * * *$ & -0.194 & $-5.35 * * *$ \\
\hline CSES & & & & & & & -0.31 & $-7.77 * * *$ & -0.29 & $-7.37 * * *$ \\
\hline$R 2$ & & .34 & & 0.39 & & 0.28 & & $\begin{array}{l}.39 \\
.41\end{array}$ & & 44 \\
\hline
\end{tabular}

Note. $* * * \mathrm{P}<0.001 ; * * \mathrm{P}<0.01 ; * \mathrm{P}<0.05$, Same as below.

C. Coping style and the construction of a core selfevaluation chain mediation model

In order to further verify the relationship between resilience, coping style, core self-evaluation and psychological health, a model was constructed with resilience as independent variable, psychological health as dependent variable, and coping style and core selfevaluation as mediating variables. The structural equation model is shown in "Fig. 1", and the fitting indexes obtained by the model are shown in "Table III". It can be seen from the fitting indexes of the model that the model is an acceptable model.

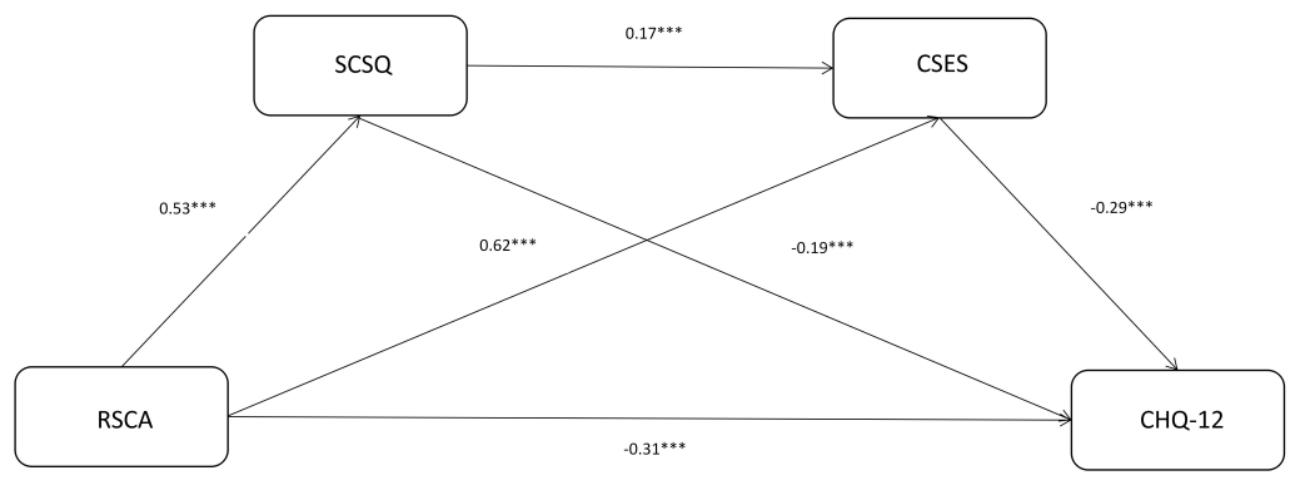

Fig. 1. Structural equation of the relationship between coping style and core self-evaluation and resilience and psychological health. 
TABLE III. RESILIENCE, COPING STYLE, CORE SELF-EVALUATION, AND FIT INDICATORS OF PSYCHOLOGICAL HEALTH MEDIATING MODELS

\begin{tabular}{ccccccc}
\hline CFI & NFI & RMSEA & GFI & IFI & AGFI & $\chi_{2} / \mathbf{d f}$ \\
\hline 0.94 & 0.91 & 0.05 & 0.96 & 0.94 & 0.93 & 2.57
\end{tabular}

As can be seen from "Fig. 1", the path coefficient hypothesis tests in the model all showed statistically significant differences $(\mathrm{P}<0.001)$. As can be seen from "Table III", the joint saliency test can be used to judge the mediating effects of the two mediating variables of coping propensity and core self-evaluation, and the chain mediation effect from resilience to psychological health is also significant. In order to further test the chained mediation effect of coping style and core selfevaluation, a bias-corrected non-parametric percent Bootstrap test was used and repeated sampling was performed 2000 times. It was found that the $95 \%$ confidence intervals of the three paths did not contain 0 , which again proved the existence of chained mediation effects. (See "Table IV")

TABLE IV. THE PATH AND UTILITY OF RESILIENCE AND PSYCHOLOGICAL HEALTH

\begin{tabular}{cccc}
\hline Mediation effect & $\begin{array}{c}\text { Intermediate } \\
\text { utility }\end{array}$ & $\begin{array}{c}\text { Mediating } \\
\text { effect ratio }\end{array}$ & $\begin{array}{c}\text { 95\% confidence } \\
\text { interval }\end{array}$ \\
\hline $\boldsymbol{R S C A} \rightarrow \boldsymbol{S C S Q} \rightarrow \boldsymbol{C H Q}-\mathbf{1 2}$ & -0.04 & $35.78 \%$ & {$[-0.05,-0.02]$} \\
$\boldsymbol{R S C A} \rightarrow \boldsymbol{C S E S} \rightarrow \boldsymbol{C H Q}-\mathbf{1 2}$ & -0.06 & $55.05 \%$ & {$[-0.08,-0.04]$} \\
$\boldsymbol{R S C A} \rightarrow \boldsymbol{S C S Q} \rightarrow \boldsymbol{C S E S} \rightarrow \boldsymbol{C H Q}-\mathbf{1 2}$ & -0.1 & $9.17 \%$ & {$[-0.02,-0.01]$} \\
\hline
\end{tabular}

\section{DISCUSSION}

Based on the environment-individual interaction model, the "evaluation-coping" theory and previous empirical research, this study explores the relationship between resilience and psychological health and the mechanism. Studies have found that resilience and core self-evaluation, coping style, and sub-dimensional positive coping styles have a negative predictive effect on the psychological health scores of disadvantaged children, that is, they have a positive predictive effect on psychological health level [26], [27], [33], [41-48]; the negative coping style has a positive predictive effect on the psychological health of disadvantaged children, that is, it has a negative predictive effect on the psychological health level, which is consistent with previous studies [31], [49]. Further research shows that resilience can not only directly affect mental health, but also indirectly affect psychological health through the mediating role of coping style and core self-evaluation. The mediation effect includes three paths: (1) mediating path through core self-evaluation; (2) mediating path through coping style; (3) chain mediating path through coping style and core self-evaluation.

\section{A. Analysis on the impact of resilience on psychological health of disadvantaged children}

Resilience, as an important ability to resist adversity, is an important factor affecting adolescents' psychological health. Previous studies have shown that there is a vicious cycle of poverty and psychological illness [50], which easily leads to psychological problems such as inferiority, depression, anxiety, and is easily affected by adverse environmental conditions [17]. It is reflected in the lack of long-term goals, positive cognition, weak emotional management ability, and easy selection of negative coping styles. Resilience training can improve the psychological and behavioral problems of adolescents [44], [45], [48]. This study found similar conclusions with disadvantaged children in southern Xinjiang, and met the "challenging" model and "steel effect". Therefore, disadvantaged children can improve their psychological health by improving their resilience.

\section{B. Mediating role of coping style between resilience and psychological health}

In this study, coping style plays a mediating role between resilience and the psychological health of disadvantaged children. Specifically, the higher the level of resilience of disadvantaged children, the higher the level of their psychological health. Coping style can significantly predict their level of psychological health, that is, individuals with high resilience tend to take an active approach when facing adversity, and better balance their physical and mental states, thereby achieving a higher level of psychological health. The results support the environment-individual interaction model and are consistent with previous research results [49], [51], [52], [53]. The intervention research on psychological health has practical significance. Disadvantaged children have relatively more obstacles to development due to lack of resources [13], [14], and in the face of adversity, they tend to choose negative coping styles [54]. At the same time, because they are at an age that is susceptible to external influences, which makes psychological and behavioral problems more common. Therefore, it is extremely important for relevant authorities to provide early intervention for disadvantaged children. 


\section{Mediating role of core self-evaluation between coping style and psychological health}

The results of this study show that core selfevaluation plays a mediating role between coping style and psychological health of junior high school students. Positive coping styles will enhance core self-evaluation and negative coping styles will reduce self-cognition. This result supports the "evaluation-response" theory [41]. At the same time, core self-evaluation can positively predict the level of psychological health, and junior high school students who take an active coping style will have a higher core self-evaluation, thereby improving their psychological health, which is consistent with the results of previous studies [42], [47]. It shows that disadvantaged children have a higher selfevaluation and a higher level of psychological health if they adopt a positive coping style. As adolescents aged 10-15 are in a period of great changes in their physical and mental development, their self-cognitive development is unstable. Interventions that first focus on coping style are also a way to improve core selfevaluation and then their psychological health. In addition, this study found that resilience can indirectly affect the psychological health of junior high school students through part of the mediation effect of core self-evaluation, which is consistent with the results of Zeng Xiaojuan's study of left-behind junior high school students [42]. This means that junior high school students with high resilience have higher core selfevaluation. It is necessary to objectively evaluate their ability and value and maintain a positive attitude when facing adversity, and believe that they can overcome the challenges they face and have a higher level of psychological health.

In summary, this study builds a chained mediating model and explores the process and mechanism of resilience affecting the psychological health of junior high school students. Coping style and core selfevaluation act as a chain mediating between resilience and the psychological health of junior high school students. It also verifies resilience $\rightarrow$ coping style $\rightarrow$ core self-evaluation $\rightarrow$ psychological health as an intermediary model, that is, adolescents with high resilience are more proactive in adopting positive coping styles in the face of adversity. While positive coping style has a positive predictive effect on core self-evaluation, and individuals with negative coping style have a negative predictive effect on core selfevaluation. Core self-evaluation is an important predictor of psychological health and explains the part of psychological health variance.

\section{RESEARCH SIGNIFICANCE AND SHORTCOMINGS}

Based on the environment-individual interaction model, "evaluation-response" theory and previous empirical research, this study explores the impact of resilience on psychological health and the mechanism in disadvantaged children in southern Xinjiang. It was found that resilience can not only positively predict the level of psychological health, but also affect psychological health through the chained mediating effect of coping style $\rightarrow$ core self-evaluation. This shows that coping style and core self-assessment are the key factors that affect resilience and improve psychological health. It expands previous research on the effects of resilience on psychological health, and adjusts or weakens the negative coping styles and outcomes that are easy to take when young people encounter adversity, which has significant negative effects. From a practical perspective, first, relevant departments should create positive conditions, encourage more social forces to pay attention to and participate in the education of disadvantaged children, and take timely preventive interventions to reduce the continuous trauma of the "scar effect" of poverty. Secondly, educators need to provide a variety of positive coping styles based on local resources at the time, pay special attention to students who often adopt negative coping styles, intervene in a timely manner, improv their cognitive style and enhancing related abilities, and pay attention to guiding students to use positive coping styles to replace negative coping styles. While guiding students to objectively evaluate their abilities and values while maintaining resilience, it is necessary to maintain a positive attitude. At the same time, these influencing factors are introduced into the psychological health classroom in order to eliminate the negative effects brought by adversity and improve their psychological health, and provide certain theoretical support for the research and intervention of psychological health.

However, there are also shortcomings in this study. First, considering factors such as research funding and ease of sampling, this study only selected schools in southern Xinjiang for investigation. The sample size is relatively small, which is not conducive to the promotion of the research results. Second, this research adopts a cross-sectional research design, which only theoretically verifies the chain mediating effect, but also shows that it is not enough to analyze the causal relationship between variables more clearly from a practical perspective. It can be combined with vertical research in the future. Third, the variables that mediate between resilience and psychological health are not limited to core self-evaluation and coping style. Other variables, such as family socioeconomic status, family parenting style, and personality characteristics that affect resilience may also be the potential mediators that affect psychological health, and there may also be interactions between these mediators and core selfevaluation and coping style. These potential mediators 
and their interaction mechanisms need to be further studied in the future.

\section{CONCLUSION}

The research can be concluded as:

- Coping style mediates between resilience and mental health.

- Coping style and core self-evaluation play a chain mediating role between resilience and mental health.

In other words, resilience has an impact on the mental health of disadvantaged children through adjustment of coping styles on the one hand, and a chain mediating effect between coping style and core self-evaluation on the other hand.

\section{References}

[1] Masten A S.Global Perspectives on Resilience in Children and Youth [J].Child Development, 2014, 85(1): 6-20.

[2] Felitti V J, Anda R F, Nordenberg D, et al. Relationship of Childhood Abuse and Household Dysfunction to Many of the Leading Causes of Death in Adults: The Adverse Childhood Experiences (ACE) Study [J]. Am J Prev Med, 2019, 56(6): 774-86.

[3] Masten, Cicchetti D. Resilience in Development: Progress and Transformation [M]. 2016 (10): 1-63.

[4] Obradović, Shaffer A, Masten A S. Risk in DevelopmentalPsychopathology: Progress and Future Directions $[\mathrm{M}] / /$ Mayes E B L, Lewis M .The Cambridge Handbook of Environment in Human Development [J]. Reference Reviews, 2012, 27 (7): 20-21.

[5] Cutuli J J , Desjardins C D ,Herbers J E ,et al.Academic Achievement Trajectories of Homeless and Highly Mobile Students: Resilience in the Context of Chronic and Acute Risk [J]. Child Development, 2013, 84 (3): 841-857.

[6] Evans G W,Dongping L,Sara Sepanski W. Cumulative Risk and Child Development [J]. Psychological Bulletin, 2013, 139 (6):1342-1396

[7] Masten A S, Narayan A J. Child Development in the Context of Disaster, War, and Terrorism: Pathways of Risk and Resilience [J]. Annual Review of Psychology, 2012, 63 (1): 227-257.

[8] Masten, A.S.; Narayan, A.J.; Silverman, W.K.; Osofsky, J.D. Children in War and Disaster. In Handbook of Child Psychology and Developmental Science [M]. Volume 4.7th ed.; Lerner, R.M., Ed.; Wiley: New Jersey, NJ, USA, 2015: 523556.

[9] Organization W H . mhGAP: Psychological Health Gap Action Programme: Scaling Up Care for Mental, Neurological and Substance Use Disorders [R].Geneva WHO, 2008.

[10] Pearson P H .Disadvantaged Children.Health, Nutrition and School Failure [J].Archives of Disease in Childhood, 1970, 45 (244): 822-822.

[11] Noble K G ,Houston S M ,Brito N H ,et al. Family Income, Parental Education and Brain Structure in Children and Adolescents [J]. Nature Neuroscience, 2015, 18 (5): 773-778.

[12] Hair N L ,Hanson J L ,Wolfe B L ,et al. Association of Child Poverty, Brain Development,and Academic Achievement [J]. JAMA Pediatrics, 2015,169 (9): 822-829.
[13] Duncan G J, Brooks-Gunn J. Family Poverty, Welfare Reform, and Child Development [J]. Child Dev, 2010, 71(1): 188-196.

[14] McLoyd, Vonnie C.Socioeconomic Disadvantage and Child Development [J]. American Psychologist, 1998, 53 (2): 185204.

[15] Jane D. McLeod and Michael J. Shanahan. Poverty, Parenting, and Children's psychological health [J]. Am Sociol Rev, 1993 , 58 (3): 351-366.

[16] Michael R. Poverty and Child Psychological Health: Natura Experiments and Social Causation [J]. Jama the Journal of the American Medical Association, 2003, 290 (15): 2063-2064.

[17] Xie Qian, Zhu Lifang, Correlation Between Psychological Health and Family Environment in Poor College Students [J] Chinese Journal of Public Health, 2008, 8(23): 55-56. (in Chinese)

[18] Woolfolk. Educational psychology.MA:Pearson Education, $2005,9^{\text {th }}$ ed

[19] Gunnar M R. Early Life Stress: What Is the Human Chapter of the Mammalian Story? [J]. Child Development Perspectives, 2016, 10(3): 178-183.

[20] Vernonfeagans L, Willoughby M, Garrettpeters P. Predictors of Behavioral Regulation in Kindergarten: Household Chaos, Parenting, and Early Executive Functions [J]. Dev Psychol, 2016, 52(3): 430-441.

[21] Katsnelson, Alla. News Feature: The neuroscience of poverty [J]. Proceedings of the National Academy of Sciences, 2015,112(51): 15530-15532.

[22] Barch D, Pagliacclo D, Belden A, et al. Effect of Hippocampal and Amygdala Connectivity on the Relationship Between Preschool Poverty and School-Age Depression [J]. Am J Psychiatry, 2016, 173(6): 625-634.

[23] Masten, Herbers J E, Cutuli J J, et al. Promoting Competence and Resilience in the School Context [J]. Professional School Counseling, 2008, 12(2): 76-84

[24] Rutter M, Psychosocial Resilience and Protective Mechanisms [J]. Am J Orthopsychiatry, 2010, 57(3): 316-331.

[25] Garmezy M A S, Tellegen A, et al. The Study of Stress and Competence in Children a Building Block for Developmenta Psychopathology [J]. Child Development, 1984, 55(1): 97-111.

[26] Chen Qin, The Relationship Between Social Support, Coping Style and Mental Health Among Needy College Students [J]. Chinese Journal of School Health, 2005, 26(8): 637-639. (in Chinese)

[27] Tenzin Drolma, You Xuqun, Effect of Sense of Cultural Alienation on psychological health in the Middle School Students of Tibet Class in Mainland China: The Mediating Role of Resilience [J]. Chinese Journal of Clinical Psychology, 2017, 25(1): 174-177. (in Chinese)

[28] Friborg O, Hjemdal O, Rosenvinge $\mathbf{J} \mathbf{H}$, et al. Resilience as a Moderator of Pain and Stress [J]. J Psychosom Res, 2006, 61(2): 213-219.

[29] Sun Lu, Zhao Jingbo, Liang Junlin, etc. A Path Analysis on Influential Factors of Psychological Health in Senior Middle School Students [J]. Chinese Journal of Clinical Psychology, 2005, 13(2): 194-195. (in Chinese)

[30] Lever J P. Poverty, Stressful Life Events, and Coping Strategies [J]. The Spanish Journal of Psychology, 2008, 11(01): 228-249.

[31] Yang Lijun, Lin Ping, Ciren Quzong, etc. Relationship Between Psychological Health and Coping Style of the Tibetan Junior Middle School Students [J]. Chinese Journal of Child Health Care, 2014, 22(12): 1299-1301. (in Chinese)

[32] Kammeyer-Mueller J D, Judge T A, Scott B A. The Role of Core Self-evaluation in the Coping Process [J]. J Appl Psychol, 2009, 94(1): 177-195. 
[33] Lei Xi, Wang Jingqun, Zhang Yuan, Core Self-evaluation and Depression: A Chain Mediating Model [J]. Chinese Journal of Clinical Psychology, 2018, 26 (04): 184-206. (in Chinese)

[34] Judge T A, Erez A, Bono J E, et al. The Core Self-evaluation Scale: Development of a measure $[\mathrm{J}]$. Personnel Psychology, 2010, 56(2): 303-331.

[35] Judge T A. Core Self-evaluation and Work Success [J]. Current Directions in Psychological Science, 2009, 18(1): 58-62.

[36] $\mathrm{Hu}$ Yueqin, Gan Yiqun, Development and Psychometric Validity of the Resilience Scale for Chinese Adolescents [J]. Acta Psychologica Sinica, 2008, 40(8): 902-912. (in Chinese)

[37] Du Jianzheng, Zhang Xiang, Zhao Yan, Reliability, Validation and Construct Confirmatory of core self-evaluation Scale [J]. Psychological Research, 2012, 5(3): 54-60. (in Chinese)

[38] Xie Ya'ning, Reliability and Validity of the Simple Coping Style Scale [J]. Chinese Journal of Clinical Psychology, 1998, (2): 114-115. (in Chinese)

[39] Li Yimin, Li Yongxin, The Factor Structure of the 12- item General Health Questionnaire: The Multi- group Analyses [J]. Exploration of Psychology, 2015, 26(4): 9-19. (in Chinese)

[40] Wen Zhonglin, Zhang Lei, Huo Jietai, etc. Testing and Application of the Mediating Effects [J]. Acta Psychologica Sinica, 2004, 36(5): 614-620. (in Chinese)

[41] Dong Junqiang, Chen Jianyong, The Impact of Students' Core Self-evaluation and the Coping Styleon Test Anxiety of Undergraduates [J]. Bulletin of Science and Technology, 2013, 29(1): 209-214. (in Chinese)

[42] Zeng Xiaojuan, Jiang Hao, Li Yongxin, Psychological Health, Resilience and Core Self-evaluation in Left-behind Rural Middle School Students [J]. Chinese psychological health Journal, 2014, 28(12): 947-950. (in Chinese)

[43] Huang Jie, Zhang Huiyong, Shang Shijie, The Mediating Effect of Resilience between Mental Stress and psychological health on College Students [J]. Studies of Psychology and Behavior, 2014, 12(06): 813-818. (in Chinese)

[44] Liu Wen, Yu Zhengyan, Lin Danhua, Resilience and Psychological Health in Children and Youth: A Meta-Analysis [J]. Studies of Psychology and Behavior, 2019, 17(1): 33-39. (in Chinese)

[45] Yang Yan, Effects of Psychological Elasticity Training on Psychological Health of Impoverished College Students [J]. Chinese Journal of School Health, 2015, 36(2): 295-297. (in Chinese)

[46] Yao Qiang, Xu Huanyu, Ji Yuanyi, etc. Multiple Group Analysis of the Relationship Among psychological health, Resilience and Self-esteem in Middle School Students of Different Gender from Rural Area in Sichuan Province [J]. Chinese Journal of School Health, 2017, 38(10): 1503-1506. (in Chinese)

[47] Zhang Xiang, Zhao Yan, Relationship Between Core-self Evaluation and psychological health of Normal School Students [J]. Chinese Journal of School Health, 2009, 30(2): 129-130. (in Chinese)

[48] Zhou Yonghong, Lv Cuifang, Xu Fanhao, On the Relationship Between Left-at-home Rural Children's Resilience and psychological health [J]. Chinese Journal of Special Education, 2013, 10): 52-59. (in Chinese)

[49] Zhu Yan, Hu Jin, Yu Yingjun, etc. Psychological Health and Coping Styles Among Rural Left-behind Chiidren [J]. Chinese Journal of School Health, 2014, 35(11): 1657-1659. (in Chinese)

[50] Lund C, DE Silva M, Plagerson S, et al. Poverty and Mental Disorders: Breaking the Cycle in Low-income and Middleincome Countries [J]. Lancet, 2011, 378(9801): 1502-1514.
[51] Wu Rui, Li Jianqiao, Liu Qin, etc. Influences of Life Event and Coping Style on Left-behind Middle School Student Psychological Health in a Three-gorge Area County [J]. Journal of Hygiene Research, 2014, 43(4): 586-590. (in Chinese)

[52] Ireand J L, Boustead R, Ireland C A. Coping Style and Psychological Health Among Adolescent Prisoners: a Study of Young and Juvenile Offenders [J]. J Adolescence, 2005, 28(3): 411-423.

[53] Meng X H, Tao F B, Wan H, et al. Coping as a Mechanism Linking Stressful Life Events and Psychological Health Problems in Adolescents [J]. Biomed Environ Sci, 2011, 24(6): 649-655.

[54] Liang Fengjuan, Health Risk Behaviors Among Poor Youth in Taiwan Province in 2015 [J]. Chinese Journal of School Health, 2018, 39(2): 307-310. (in Chinese) 